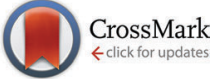

Cite this: Phys. Chem. Chem. Phys., 2016, 18, 9437

Received 14th December 2015, Accepted 2nd March 2016

DOI: $10.1039 / c 5 c p 07713 c$

www.rsc.org/pccp

\title{
Fabrication of FeOOH hollow microboxes for purification of heavy metal-contaminated water $\dagger$
}

\begin{abstract}
Sida Wang, ${ }^{\text {ab }}$ Huachun Lan, ${ }^{a}$ Huijuan Liu*a and Jiuhui $\mathrm{Qu}^{\mathrm{a}}$
$\mathrm{FeOOH}$, a frequently used adsorbent, has been widely applied in purifying aqueous heavy metals, and its performance can be greatly improved by enlarging the number of surface active sites. To this end, we fabricated $\mathrm{FeOOH}$ hollow microboxes constructed from numerous 2D nanosheets via a templateengaged reaction between Prussian blue (PB) and $\mathrm{NaOH}$ solution. With combined observations from $\mathrm{X}$-ray powder diffraction (XRD), scanning electron microscopy (SEM), transmission electron microscopy (TEM) and X-ray photoelectron spectroscopy (XPS), we confirmed that the hollow microboxes corroded from PB were composed of ample frizzy $\mathrm{FeOOH}$ nanosheets, which ensured extensive exposure of the surface active sites. Moreover, the $\mathrm{FeOOH}$ microboxes were utilized as an adsorbent in the removal of heavy metals (As(III), As(V) and Se(IV)) from water and the maximum adsorption capacities were reached up to $192.19 \mathrm{mg} \mathrm{g}^{-1}, 250.0 \mathrm{mg} \mathrm{g}^{-1}$ and $169.9 \mathrm{mg} \mathrm{g}^{-1}$ at $\mathrm{pH}=7.0,4.0$ and 5.0, respectively. The superior adsorptive performance of the $\mathrm{FeOOH}$ microboxes was derived from their large content of reactive exposed hydroxyl groups, which was unambiguously confirmed by X-ray adsorption fine structure spectroscopy (XAFS), as well as by surface site density analysis.
\end{abstract}

\section{Introduction}

Adsorption has been considered as a promising technology for the removal of heavy metal-based oxyanions from industrial effluents and natural waters. Various efforts have been focused on the development of novel sorbents for high removal performance, such as iron oxides, ${ }^{1}$ activated carbon, ${ }^{2}$ alumina, ${ }^{3}$ clays ${ }^{4}$ etc. to adsorb heavy metals from water. Among the numerous different types of adsorbents, Fe containing materials have attracted special attention due to their low cost and good adsorption capacity towards arsenic, ${ }^{5,6}$ antimony $^{7}$ and selenium. ${ }^{8}$ Akaganèite $(\beta \text {-FeOOH })^{9}$ and ultrafine $\mathrm{FeOOH}^{10}$ have been synthesized and used for $\mathrm{As}(\mathrm{v})$ removal with adsorption capacities of $60 \mathrm{mg} \mathrm{g}^{-1}$ and $37.3 \mathrm{mg} \mathrm{g}^{-1}$, respectively. Additionally, a novel chitosan-iron oxyhydroxide, ${ }^{11}$ with an adsorption capacity of $7.2 \mathrm{mg} \mathrm{g}^{-1}$ for As(III), was fabricated and the adsorption mainly involved complex reactions between the heavy metals and active hydroxyl groups. ${ }^{6,11-13}$ Thus, to pursue high adsorptive performance, it is reasonable to amplify the number of surface active hydroxyl groups of $\mathrm{FeOOH}$ via rational regulation of its structure.

\footnotetext{
${ }^{a}$ Key Laboratory of Drinking Water Science and Technology, Research Center for Eco-Environmental Science, Chinese Academy of Sciences, Beijing 100085, China. E-mail: hjliu@rcees.ac.cn

${ }^{b}$ University of Chinese Academy of Science, Beijing 100039, China

$\dagger$ Electronic supplementary information (ESI) available. See DOI: 10.1039/ c5cp07713c
}

Currently, two-dimensional (2D) structures have received considerable attention due to their controllable size, shape, composition and the presence of extensively exposed surface active sites, and have also been applied in a wide spectrum of fields, such as energy storage and conversion, ${ }^{14}$ catalysis, ${ }^{15}$ adsorbents $^{16,17}$ and so on. To this end, synthesizing $\mathrm{FeOOH}$ into $2 \mathrm{D}$ nanosheets is an appropriate method to promote its adsorptive performance. However, the high surface energy and interlayer van der Waals attraction of $2 \mathrm{D}$ nanosheets may restrict the exposure of its surface active sites, due to the inevitable agglomeration and condensation. ${ }^{18}$ To overcome this restriction, assembling these $2 \mathrm{D} \mathrm{FeOOH}$ nanosheets into threedimensional (3D) hollow structures should be an efficient way to avoid agglomeration and retain the advantages of lamellar 2D nanosheets to a large extent. ${ }^{19-22}$ In previous studies, numerous methods were utilized to fabricate hollow structures with well-defined interior voids and adequately exposed active sites for various applications, such as gas sensing, selective permeability and light degradation..$^{23-25}$ However, among these fabrication processes, the growth of desirable shells by using a sacrificial template was the most feasible approach, while the complicated synthetic conditions have restricted their production in large quantity. ${ }^{26}$ Hence, it is of significance to choose moderate experimental conditions to assemble $\mathrm{FeOOH}$ nanosheets into hollow structures with abundant exposed surface hydroxyl groups.

In this work, $\mathrm{FeOOH}$ microboxes with a hollow structure assembled from numerous 2D nanosheets were prepared. 
The $\mathrm{FeOOH}$ microboxes were characterized by BET specific surface area, scanning electron microscopy (SEM), transmission electron microscopy (TEM) and X-ray photoelectron spectroscopy (XPS). Furthermore, the extensively exposed active sites on its obviously rough surface were analyzed in detail by X-ray adsorption fine spectroscopy (XAFS). In combination with measurements of adsorption kinetics at low concentration and adsorption isotherms, the relationship between quality and quantity of these exposed hydroxyl groups was further discussed.

\section{Experimental methods}

\subsection{Materials}

All chemical reagents were purchased and used without further purification, including polyvinylpyrrolidone (PVP) $\left(M_{\mathrm{w}}=1300000\right.$, Aldrich), ferric chloride $\left(\mathrm{FeCl}_{3} \cdot 6 \mathrm{H}_{2} \mathrm{O}\right.$ ) (analytical reagent), ferric ferrocyanide $\left(\mathrm{K}_{4} \mathrm{Fe}(\mathrm{CN})_{6} \cdot 3 \mathrm{H}_{2} \mathrm{O}\right)$ (analytical reagent), hydrochloric acid ( $\mathrm{HCl}$ ) (guaranteed reagent, 36\%), sodium arsenate $\left(\mathrm{Na}_{2} \mathrm{HAsO}_{4} \cdot 7 \mathrm{H}_{2} \mathrm{O}\right)$ (analytical reagent), sodium arsenite $\left(\mathrm{NaAsO}_{2}\right)$ (analytical reagent) and sodium selenite $\left(\mathrm{Na}_{2} \mathrm{SeO}_{3}\right)$ (analytical reagent). All the stock solutions were prepared with de-ionized water for both material preparation and adsorption experiments.

\subsection{Synthesis of FeOOH microboxes}

FeOOH microboxes were synthesized via a simple chemical reaction between the prepared Prussian blue (PB) and $\mathrm{NaOH}$ solution. Briefly, $3.8 \mathrm{~g}$ PVP was first dissolved into $50 \mathrm{~mL} 0.1 \mathrm{M}$ $\mathrm{HCl}$ solution followed by the addition of $110 \mathrm{mg} \mathrm{K}_{4} \mathrm{Fe}(\mathrm{CN})_{6}$. After vigorous stirring for $40 \mathrm{~min}$ at room temperature, the mixture was transferred to an oven at $80{ }^{\circ} \mathrm{C}$ for $24 \mathrm{~h}$. The obtained blue precipitate $\left(\mathrm{K}_{4}\left[\mathrm{Fe}(\mathrm{CN})_{6}\right]_{3}, \mathrm{~PB}\right)$ was centrifuged and washed for several cycles with water and ethanol and finally dispersed into $10 \mathrm{~mL}$ absolute ethanol for further use. The FeOOH microboxes were obtained by the reaction between as-prepared $\mathrm{PB}$ and $0.1 \mathrm{M} \mathrm{NaOH}$ solution at room temperature. Typically, $10 \mathrm{~mL}$ of the above PB suspension was mixed with $35 \mathrm{~mL} \mathrm{NaOH}$ aqueous solution. After the mixture was shaken by end-over-end rotation for $12 \mathrm{~h}$, the as-prepared product was collected by rinse-centrifugation cycles. Correspondingly, traditional FeOOH prepared via a commonly used method, was prepared for comparison. ${ }^{27}$

\subsection{Characterizations of FeOOH microboxes}

The morphology and elemental composition of FeOOH microboxes were observed by a field-emission scanning electron microscope (FESEM) combined with an energy dispersive spectrometer (EDS) (Hitachi S4800, Japan). In addition, highresolution electron microscopy (HRTEM) (JEOL JEM-2100F, Japan) was used to directly obtain the specific pore distribution, and the pore distribution and specific surface area were determined by nitrogen adsorption and desorption on an automatic specific surface area and micropore physical adsorption instrument (Micromeritics ASPA 2020 HD88, USA). The crystal structure of samples was characterized by XRD (X'Pert Pro PW 3040-Pro, PANalytical Inc.) using $\mathrm{Cu} \mathrm{K} \alpha$ irradiation operating at $40 \mathrm{kV}$ and
$40 \mathrm{~mA}$ with a fixed slit. The surface composition of $\mathrm{FeOOH}$ microboxes was analyzed by XPS using $\mathrm{Al} \mathrm{K}_{\alpha}(1486.7 \mathrm{eV})$ as the radiation source. The binding energy was calibrated with reference to the $\mathrm{C} 1 \mathrm{~s}$ peak at $284.8 \mathrm{eV}$. Furthermore, XAFS was used to characterize the electronic configurations and local coordination structures. The X-ray adsorption near-edge structure (XANES) and extended X-ray absorption fine-structure (EXAFS) spectroscopy of Fe $\mathrm{K}$ edges in $\mathrm{FeOOH}$ and reference samples were measured in transmission mode at room temperature. The storage ring was operated at $3.5 \mathrm{GeV}$ with $200 \mathrm{~mA}$ as an average storage current (BL14W1 beam line, Shanghai Synchrotron Radiation Facility (SSRF)). Data were analyzed with standard procedures using Athena and Artemis from the IFeffit 1.2.11 software package. ${ }^{28}$

\subsection{Adsorption experiments}

All the experiments were carried out by agitating a fixed mass of adsorbent $\left(250 \mathrm{mg} \mathrm{L}^{-1}\right)$ in $50 \mathrm{~mL}$ centrifuge tubes with contaminant-containing solution at various concentrations. Moreover, the temperature was chosen at $25 \pm 1{ }^{\circ} \mathrm{C}$ according to our preliminary experiments (Fig. S1, ESI †). The initial $\mathrm{pH}$ values of the solutions were precisely adjusted with $\mathrm{HCl}$ $(0.01 \mathrm{M})$ or $\mathrm{NaOH}(0.01 \mathrm{M})$ solutions. After adsorption had taken place for a designated period of time, samples were taken out from the mixture and filtered by a $0.22 \mu \mathrm{m}$ polytetrafluoroethylene (PTFE) membrane filter and analyzed for the heavy metal concentration by inductively coupled plasma-optical emission spectrometry (ICP-OES) (Agilent 5100, USA) or inductively coupled plasma mass spectrometry (ICP-MS) (PerkinElmer Optima 2000, USA).

The amount of metal ions adsorbed on the as-prepared adsorbent at adsorption equilibrium, $Q_{\mathrm{e}}\left(\mathrm{mg} \mathrm{g}^{-1}\right)$, was calculated according to eqn (1):

$$
Q_{\mathrm{e}}=\frac{\left(C_{0}-C_{\mathrm{e}}\right) \times V}{W}
$$

where $C_{0}$ and $C_{\mathrm{e}}$ are the initial and equilibrium metal ion concentrations $\left(\mathrm{mg} \mathrm{L}^{-1}\right)$ respectively, determined by ICP-OES or ICP-MS; $V$ is the total volume of metal ion solution (L), and $W$ is the weight of added adsorbent $(\mathrm{g})$.

2.4.1 Adsorption isotherms. In the adsorption isotherm study, $10 \mathrm{mg}$ of the $\mathrm{FeOOH}$ microboxes adsorbent was added to $40 \mathrm{~mL}$ heavy metal-containing solutions (As(III) ranged from 5 to $200 \mathrm{mg} \mathrm{L}^{-1}, \mathrm{As}(\mathrm{v})$ from 10 to $200 \mathrm{mg} \mathrm{L}^{-1}$, while Se(Iv) from 1 to $100 \mathrm{mg} \mathrm{L}^{-1}$ ). The initial $\mathrm{pH}$ was controlled at 4 to 9 to investigate the effect of $\mathrm{pH}$. The mixtures were shaken at $100 \mathrm{rpm}$ for $24 \mathrm{~h}$, which was verified to be sufficient for adsorption equilibrium (Fig. S1d, ESI $\dagger$ ).

2.4.2 Adsorption kinetics for heavy metals at low concentration. In order to predict the adsorption effect in practical application, the adsorption efficiency of $\mathrm{FeOOH}$ microboxes for As(III), As(v) and Se(Iv) at low concentration was also investigated. $20 \mathrm{mg} \mathrm{FeOOH}$ microboxes adsorbent was added into $80 \mathrm{~mL}$ of $1 \mathrm{mg} \mathrm{L}^{-1}$ As solution $\left(0.5 \mathrm{mg} \mathrm{L}^{-1}\right.$ of As(III) and $0.5 \mathrm{mg} \mathrm{L}^{-1}$ $\mathrm{As}(\mathrm{v}))$ at $\mathrm{pH} 7$ or $1 \mathrm{mg} \mathrm{L}^{-1}$ of $\mathrm{Se}(\mathrm{Iv})$ at $\mathrm{pH}$ 6. The mixture was shaken at $100 \mathrm{rpm}$, samples of $1 \mathrm{~mL}$ for each were taken at 


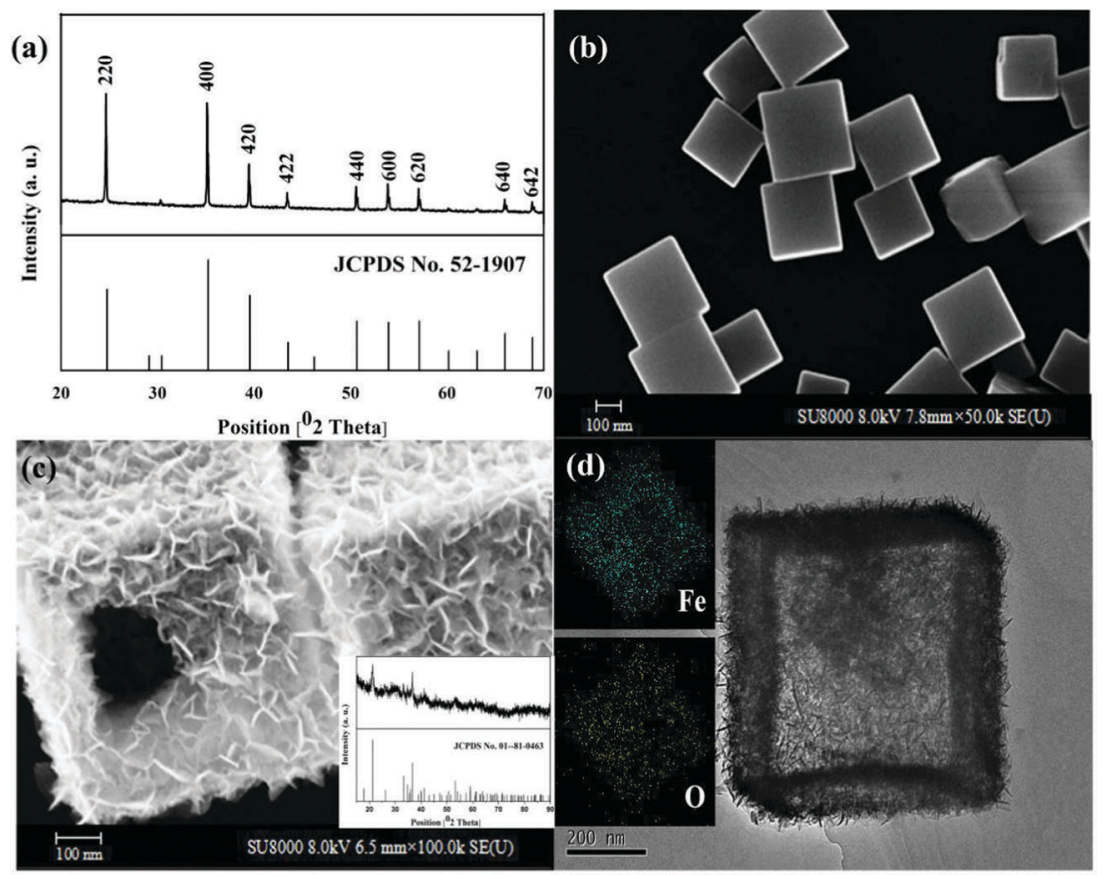

Fig. 1 (a) XRD patterns and (b) SEM image of PB microcubes precursor; (c) SEM image and (inset) XRD patterns of FeOOH microboxes, (d) TEM images and (inset) EDX spectroscopic analysis of the as-prepared FeOOH microboxes.

different time intervals, and the metal concentrations were analyzed.

\section{Results and discussion}

\subsection{Characterizations of FeOOH microboxes}

The physical and chemical characteristics of the as-synthesized FeOOH hollow microboxes were analyzed by a variety of methods. According to the results of XRD (Fig. 1a), all the diffraction peaks are in good agreement with the face-centered-cubic (FCC) structured $\mathrm{Fe}_{4}\left[\mathrm{Fe}(\mathrm{CN})_{6}\right]_{3}$ (PB) (JCPDS card no. 52-1907).

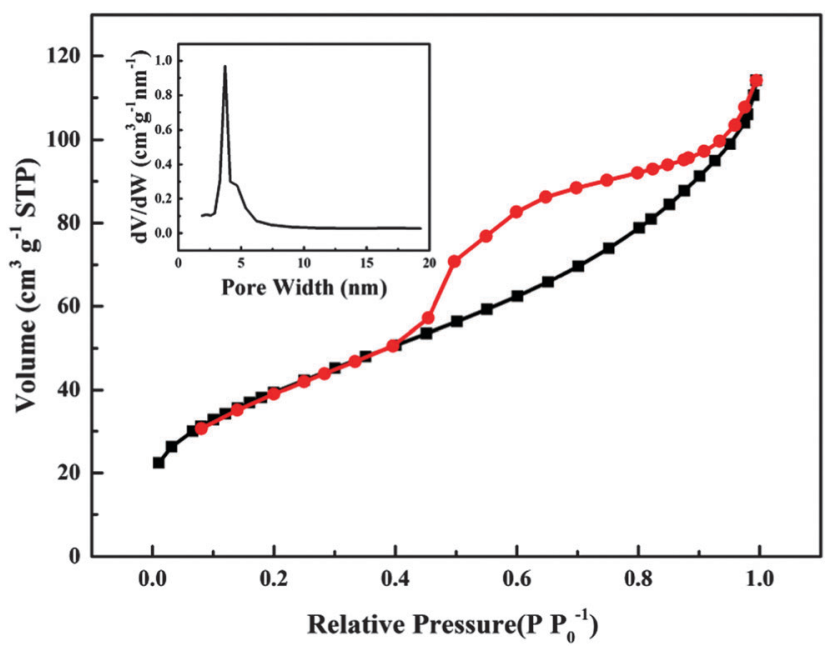

Fig. $2 \mathrm{~N}_{2}$ adsorption/desorption isotherm and pore size distribution curves of $\mathrm{FeOOH}$ microboxes.
In addition, these highly uniform $\mathrm{PB}$ nanocubes with side lengths ranging from 300 to $400 \mathrm{~nm}$ were observed as shown in Fig. 1b. In contrast to the reactants' concentration at $0.02 \mathrm{M}$, after reaction with $0.2 \mathrm{M} \mathrm{NaOH}$ solution at room temperature, the products were changed from the coarse solid cubes to hollow structures assembled from numerous frizzy nanosheets (Fig. S2b, ESI, $\dagger$ Fig. 1c). According to the element-mapping analysis shown in Fig. 1d, the elements of Fe and $\mathrm{O}$ were welldistributed over the surface of the microboxes, which was primary determined as $\mathrm{FeOOH}$ based on the results of the

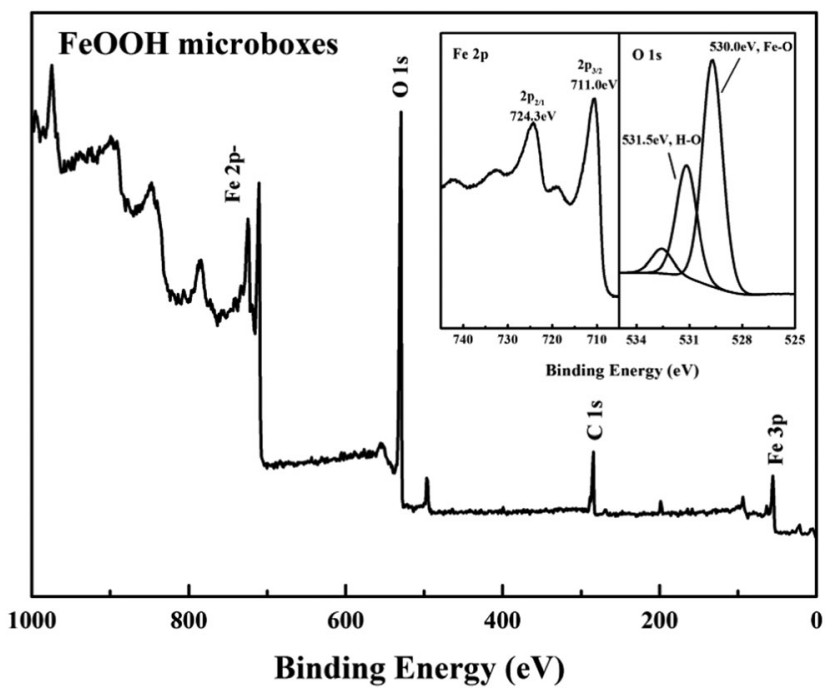

Fig. 3 Full scan $\mathrm{X}$-ray photoelectron spectrum of $\mathrm{FeOOH}$ microboxes. Inset: $\mathrm{Fe} 2 \mathrm{p}$ and $\mathrm{O}$ 1s results of the $\mathrm{FeOOH}$ microboxes. 


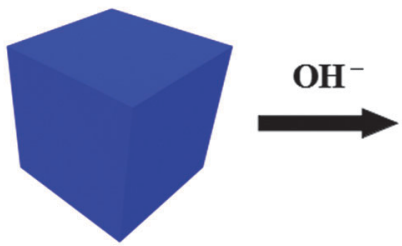

$\mathrm{Fe}_{4}\left[\mathrm{Fe}(\mathrm{CN})_{6}\right]_{3}$

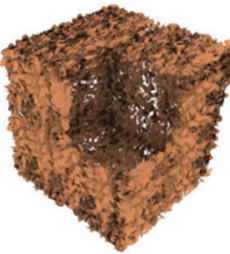

FeOOH microboxes

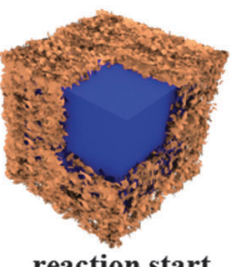

reaction start from the surface

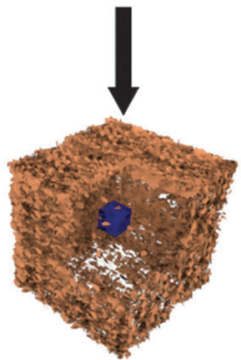

nanosheets precipitation
Scheme 1 Schematic illustration of the formation of $\mathrm{FeOOH}$ hollow microboxes and the accumulation of nanosheets at the surface.

XRD patterns (Fig. 1c inset). Moreover, a sharp pore size distribution with an average size of $4 \mathrm{~nm}$ was obtained using the Barrett-Joyner-Halenda method (Fig. 2 inset), and the BET surface area of the hollow microboxes was measured to be $147.28 \mathrm{~m}^{2} \mathrm{~g}^{-1}$ (Fig. 2).

In order to determine the electronic and chemical structure of the as-prepared microboxes, XPS measurements were carried out. As depicted in Fig. 3, two of the compositional elements in $\mathrm{FeOOH}$ microboxes, Fe and $\mathrm{O}$, were detected along with adventitious carbon. The two main peaks at 724.3 and $711 \mathrm{eV}$ were assigned to the Fe $2 \mathrm{p}_{1 / 2}$ and $\mathrm{Fe} 2 \mathrm{p}_{3 / 2}$ spin-orbit peaks (inset in Fig. 2). ${ }^{29}$ In addition, the $\mathrm{O} 1 \mathrm{~s}$ peak at $530.0 \mathrm{eV}$ could be derived from $\mathrm{Fe}-\mathrm{O}$, and was associated with the crystal lattice oxygen species, ${ }^{30}$ while the peak at $531.5 \mathrm{eV}$ derived from the hydroxyl oxygen. ${ }^{31}$ Combining with the FTIR results (Fig. S3, ESI $\dagger$ ), it was reasonable to conclude that the synthesized $\mathrm{FeOOH}$ hollow microboxes were composed of plenty of $\mathrm{FeOOH}$ nanosheets, which were based on the reaction involving etching of the unique metal-organic frameworks (MOFs) template (PB), according to eqn (2). ${ }^{32}$ The formation process of $\mathrm{FeOOH}$ microboxes followed the strategy illustrated in Scheme 1.

$$
12 \mathrm{OH}_{(\mathrm{aq})}{ }^{-}+\mathrm{Fe}_{4}\left[\mathrm{Fe}(\mathrm{CN})_{6}\right]_{3(\mathrm{~s})} \rightarrow 3 \mathrm{Fe}(\mathrm{CN})_{6(\mathrm{aq})}{ }^{4-}+4 \mathrm{Fe}(\mathrm{OH})_{3(\mathrm{~s})}
$$

When dispersed in solution at $\mathrm{pH}=13$, the surface of the $\mathrm{PB}$ nanocubes are converted to $\mathrm{Fe}(\mathrm{OH})_{3}$ colloids initially based on the chemical reaction in eqn (2), while the solid interior retained its original shape at that time. At the beginning of the etching
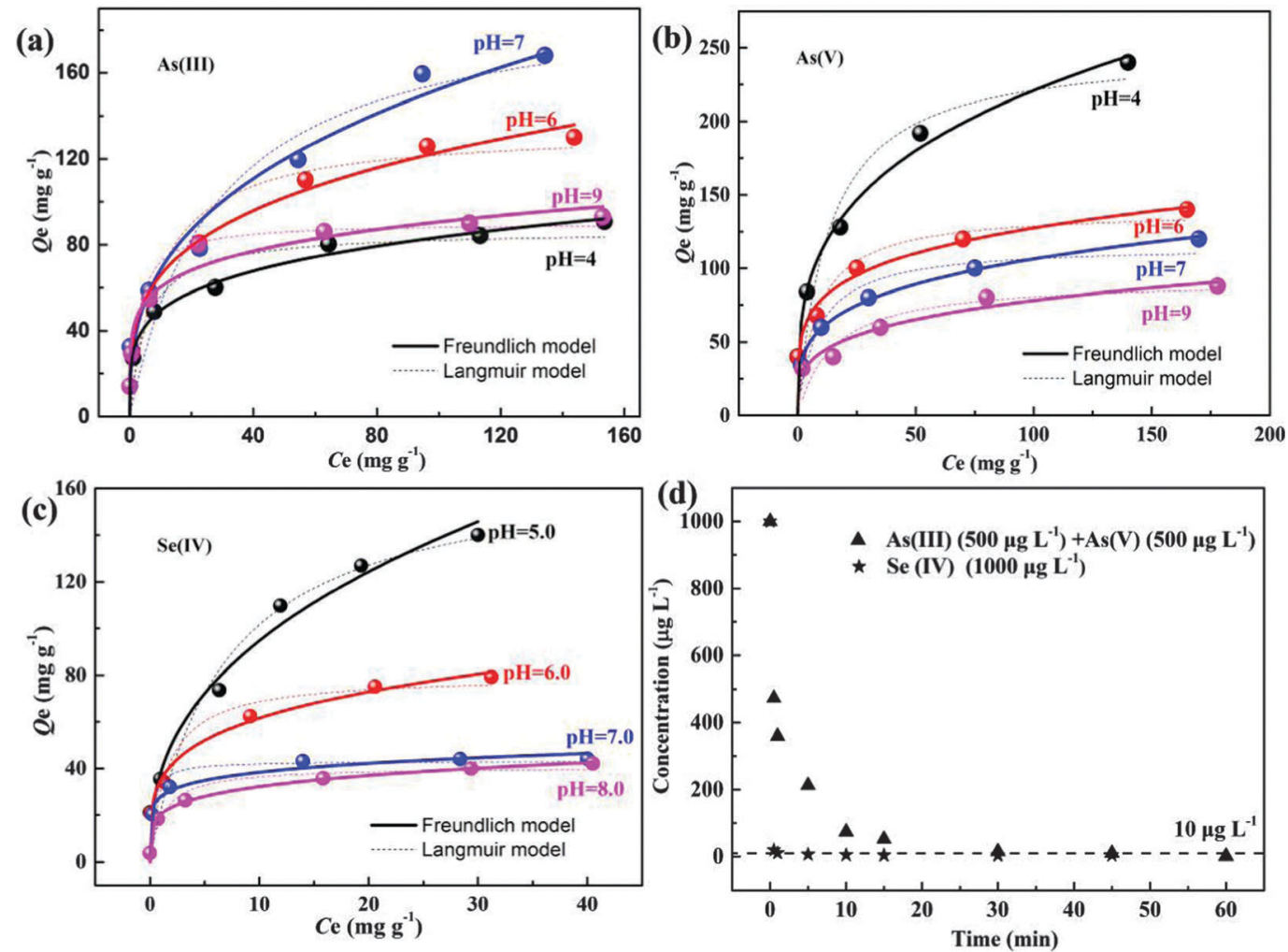

Fig. 4 Langmuir and Freundlich adsorption isotherms, showing the linear form of the curves, and the adsorption kinetics of heavy metal adsorption on $\mathrm{FeOOH}$ microboxes with a dosage of $250 \mathrm{mg} \mathrm{L}^{-1}$ : (a) adsorption isotherm of As(III) with initial concentration ranges from 5 to $200 \mathrm{mg} \mathrm{L}^{-1}$ at different $\mathrm{pH}$ conditions; (b) adsorption isotherm of As(v) with initial concentration ranges from 10 to $200 \mathrm{mg} \mathrm{L}^{-1}$ at different pH conditions; (c) adsorption isotherm of Se(Iv) with initial concentration ranges from 1 to $100 \mathrm{mg} \mathrm{L}^{-1}$ at different $\mathrm{pH}$ conditions and (d) removal efficiencies of As(III), As(v) and Se(Iv) at low initial concentration at neutral $\mathrm{pH}$ value. 
reaction, the $\mathrm{PB}$ surface became rough, whereas the main structure remained unchanged (Fig. S4a, ESI $\dagger$ ). Once the concentration of $\mathrm{Fe}(\mathrm{OH})_{3}$ reached a critical value, it easily deposited around the $\mathrm{Fe}(\mathrm{OH})_{3}$ nuclei on the surface of PB (Fig. S4b, ESI $\dagger$ ), resulting in the formation of $2 \mathrm{D} \mathrm{FeOOH}$ nanosheets. Simultaneously, the as-formed $\mathrm{FeOOH}$ nanosheets slightly twisted (Fig. S4c-e, ESI $\dagger$ ), in order to decrease the surface energy in aqueous solution. This twisting resulted in different types of pores, thereby providing a passageway for the outward flow of $\mathrm{Fe}(\mathrm{CN})_{6}{ }^{4-}$ and inward flow of $\mathrm{OH}^{-}$. With the reaction time extended, the interior $\mathrm{PB}$ turned into the surface and converted to $\mathrm{FeOOH}$ nanosheets until the total disintegration of $\mathrm{PB}$, and this decreasing of the volume of $\mathrm{PB}$ could be observed after etching for $5 \mathrm{~min}$ (Fig. S4f, ESI $\dagger$ ). Meanwhile, to minimize the total surface energy, these newly formed $\mathrm{FeOOH}$ nanosheets tended to accumulate with the former ones by crosslinking via hydrogen bonds among surface hydroxyl groups, ${ }^{33}$ which further amplified the active sites. As the $\mathrm{FeOOH}$ nanosheets were linked based on the template provided by the PB nanocubes, the hollow microcubic structures comprised of twisted $\mathrm{FeOOH}$ nanosheets were ultimately formed. With the retained 2D FeOOH nanosheets and abundant surface active groups, these FeOOH microboxes were provided with high chemical reactivity.

\subsection{Adsorption experiments for heavy metals}

The FeOOH microboxes were demonstrated to exhibit a special hollow structure, which may enable superior transfer and diffusion of substances, and we expected that the as-synthesized FeOOH with hollow microboxes could function as an adsorbent with superior performance for this reason. To confirm this, the

Table 1 Adsorption isotherm parameters based on the Langmuir and Freundlich model and experimental maximum adsorption capacity $Q_{\text {max,exp }}$ values at the optimum conditions

\begin{tabular}{|c|c|c|c|c|c|c|c|}
\hline \multirow[b]{2}{*}{ Metal ions } & \multirow[b]{2}{*}{$\begin{array}{l}Q_{\max , \exp } \\
\left(\mathrm{mg} \mathrm{g}^{-1}\right)\end{array}$} & \multicolumn{3}{|c|}{ Langmuir } & \multicolumn{3}{|c|}{ Freundlich } \\
\hline & & $\begin{array}{l}Q_{\max , \mathrm{cal}} \\
\left(\mathrm{mg} \mathrm{g}^{-1}\right)\end{array}$ & $b$ & $R^{2}$ & $k$ & $n$ & $R^{2}$ \\
\hline As(III) & 167.96 & 192.19 & 0.03 & 0.90 & 28.77 & 2.78 & 0.97 \\
\hline $\operatorname{As}(\mathrm{v})$ & 240.14 & 250.01 & 0.08 & 0.86 & 56.60 & 3.38 & 0.91 \\
\hline $\mathrm{Se}(\mathrm{IV})$ & 140.09 & 169.88 & 0.15 & 0.95 & 38.38 & 2.55 & 0.96 \\
\hline
\end{tabular}

adsorption kinetics of arsenic (As(v) and As(III)) and selenium (Se(Iv)) at low concentration and the adsorption isotherms of these three heavy metal ions were evaluated.

As depicted in Fig. 4, the adsorption capacities of $\operatorname{As}(\mathrm{v})$ and $\mathrm{Se}(\mathrm{Iv})$ increased with decreasing $\mathrm{pH}$ value. According to thermodynamic calculations, the positively charged surface of the $\mathrm{FeOOH}$ microboxes would likely prefer the adsorption of the monovalent As(v) oxyanion, $\mathrm{H}_{2} \mathrm{AsO}_{4}{ }^{-34}$, which was the dominant species $\left(\mathrm{p} K_{1}=2.24, \mathrm{p} K_{2}=6.76, \mathrm{p} K_{3}=11.60\right)$. Therefore, the best adsorption performance at $\mathrm{pH}=4$ was due to the strong electrostatic effect between the negative As species and the positive $\mathrm{FeOOH}$ surface (Fig. S5, ESI $\dagger$ ), while the lowest adsorption capacity was observed at $\mathrm{pH}=9$. Similar to $\mathrm{As}(\mathrm{v})$, the main species of $\mathrm{Se}(\mathrm{Iv})$ was $\mathrm{SeO}_{4}{ }^{2-}$ at pH $4\left(\mathrm{p} K_{1}=-3.0, \mathrm{p} K_{2}=1.66\right)^{35}$ which was also in favor of the electrostatic attraction. However, the peak As(III) adsorption was observed at $\mathrm{pH}=7.0$, which was in good agreement with the $\mathrm{pH}$-dependent As speciation and the surface charge of the $\mathrm{FeOOH}$ sorbent (Fig. 4a). The predominate species of $\mathrm{As}(\mathrm{III})$ was $\mathrm{H}_{3} \mathrm{AsO}_{3}$ in the $\mathrm{pH}$ range from 4.0 to 9.0, therefore the adsorption was facilitated by electrostatic attraction between the neutral species and the negatively charged adsorbent surface at $\mathrm{pH}$ above the isoelectric point (IEP) of the adsorbent. At pH lower than 7.0, the active sites for adsorption were easily occupied by the protons, resulting in the decreased adsorption performance. Meanwhile, at $\mathrm{pH}$ greater than 7.0, the competition from hydroxyls for the adsorption sites decreased the adsorption efficiency as well.

Furthermore, Langmuir (eqn (3)) and Freundlich (eqn (4)) isotherm models were used to fit the experimental data:

$$
\begin{gathered}
Q_{\mathrm{e}}=\frac{a b C_{\mathrm{e}}}{\left(1+b C_{\mathrm{e}}\right)} \\
Q_{\mathrm{e}}=k\left(C_{\mathrm{e}}\right)^{\frac{1}{n}}
\end{gathered}
$$

where $Q_{\mathrm{e}}\left(\mathrm{mg} \mathrm{g}^{-1}\right)$ is the adsorption capacity of metal ions at equilibrium, and $C_{\mathrm{e}}\left(\mathrm{mg} \mathrm{L}^{-1}\right)$ is the equilibrium concentration of metal ions. $k$ is the Freundlich isotherm constant, indicating the relative sorption ability of the adsorbent $\left(\mathrm{mg} \mathrm{g}^{-1}\right)$, and $1 / n$ is the sorption intensity. The Langmuir constant $b$ is indicative of the free energy of sorption $\left(\mathrm{L} \mathrm{mg}^{-1}\right)$ and $a$ is the maximum adsorption ability of the adsorbent $\left(\mathrm{mg} \mathrm{g}^{-1}\right)$.

\begin{tabular}{|c|c|c|c|c|c|c|}
\hline Metals ions & Adsorbents & Initial pH & Concentration range $\left(\mathrm{mg} \mathrm{L}^{-1}\right)$ & $Q_{\max }\left(\mathrm{mg} \mathrm{g}^{-1}\right)$ & Most suitable model & Ref. \\
\hline & $\mathrm{TiO}_{2}-\mathrm{CNT}$ & 7 & $0.1-1$ & 1.3 & Freundlich & 5 \\
\hline & FeOOH microboxes & 4 & $5-200$ & 250.01 & Freundlich & This study \\
\hline \multirow[t]{2}{*}{$\operatorname{As}(\mathrm{III})$} & $\mathrm{TiO}_{2}-\mathrm{CNT}$ & 7 & $0.1-1$ & 1.8 & Freundlich & 5 \\
\hline & FeOOH microboxes & 7 & $5-200$ & 239.79 & Langmuir & This study \\
\hline \multirow[t]{3}{*}{$\operatorname{Se}(\mathrm{Iv})$} & MGO & 2 & $0.05-500$ & 23.81 & Langmuir & 13 \\
\hline & Fe-Mn hydrous oxides & 4 & $5-500$ & 41.02 & Freundlich & 44 \\
\hline & FeOOH microboxes & 5 & $1-100$ & 169.88 & Freundlich & This study \\
\hline
\end{tabular}

Table 2 Maximum As(III), As(v) and Se(IV) adsorption capacities ( $\left.Q_{\max }\right)$ of various adsorbents 
According to the fitting results (listed in Table 1), the correlation coefficients $\left(R^{2}\right)$ of the Freundlich model of As(III), $\operatorname{As}(\mathrm{v})$ and Se(Iv) were higher than those of the Langmuir model. Table 2 lists the adsorption capacities of FeOOH hollow microboxes and other comparable adsorbents from previous literature, such as ceria hollow nanospheres, ${ }^{36}$ titanium dioxidecoated carbon nanotubes $\left(\mathrm{TiO}_{2}-\mathrm{CNT}\right),{ }^{5}$ GO-Fe composites, ${ }^{37}$ chitosan-iron oxyhydroxide $(\mathrm{CFOH}),{ }^{11}$ magnetic nanoparticle-graphene oxide $(\mathrm{MGO})^{13}$ and $\mathrm{Fe}-\mathrm{Mn}$ hydrous oxides. $^{38}$ The maximum adsorption capacities of the $\mathrm{FeOOH}$ hollow microboxes were $192.19 \mathrm{mg} \mathrm{g}^{-1}$ for As(III), $250.01 \mathrm{mg} \mathrm{g}^{-1}$ for $\mathrm{As}(\mathrm{v})$ and $169.88 \mathrm{mg} \mathrm{g}^{-1}$ for Se(Iv), in good agreement with the experimental values. These values were much higher than those from ceria hollow nanospheres with the maximum adsorption capacity of $22.4 \mathrm{mg} \mathrm{g}^{-1}$ at $\mathrm{pH}=3$ for $\mathrm{As}(\mathrm{v}),{ }^{39}$ and more than 4 times higher than that of $\mathrm{Fe}-\mathrm{Mn}$ hydrous oxides at $\mathrm{pH}=4$ for $\mathrm{Se}(\mathrm{Iv})$. $^{38}$

The results of adsorption at low heavy metal concentration on the as-synthesized FeOOH microboxes are displayed in Fig. 4d. The initial concentrations of arsenic $(\operatorname{As}(\mathrm{III}): \operatorname{As}(\mathrm{v})=$ $1: 1)$ and selenium were both $1 \mathrm{mg} \mathrm{L}^{-1}$ with $\mathrm{pH}$ values of 6 and 7 respectively. Se(Iv) could be purified in less than $30 \mathrm{~s}$ with an equilibrium concentration lower than $10 \mu \mathrm{g} \mathrm{L}^{-1}$, and the response time for arsenic was $15 \mathrm{~min}$. These fast purification processes suggested the excellent affinity of the as-synthesized FeOOH microboxes for the contaminants in solution. Furthermore, the stability of the $\mathrm{FeOOH}$ microboxes after recovery by $\mathrm{NaOH}$ was investigated (see in ESI $\dagger$ ), and the amount of heavy metals adsorbed in the $\mathrm{FeOOH}$ microboxes during five consecutive sorption-desorption cycles are shown in Fig. 5. After testing for 5 consecutive cycles, the adsorption capacities of the metals were only slightly decreased by $14 \%, 17 \%$ and $15 \%$ for $\mathrm{As}(\mathrm{III}), \mathrm{As}(\mathrm{v})$ and $\mathrm{Se}(\mathrm{IV})$, respectively, in contrast to the first-use. The facile recovery and high stability of the hollow structured adsorbent demonstrates its significant potential in the industrial-scale applications.

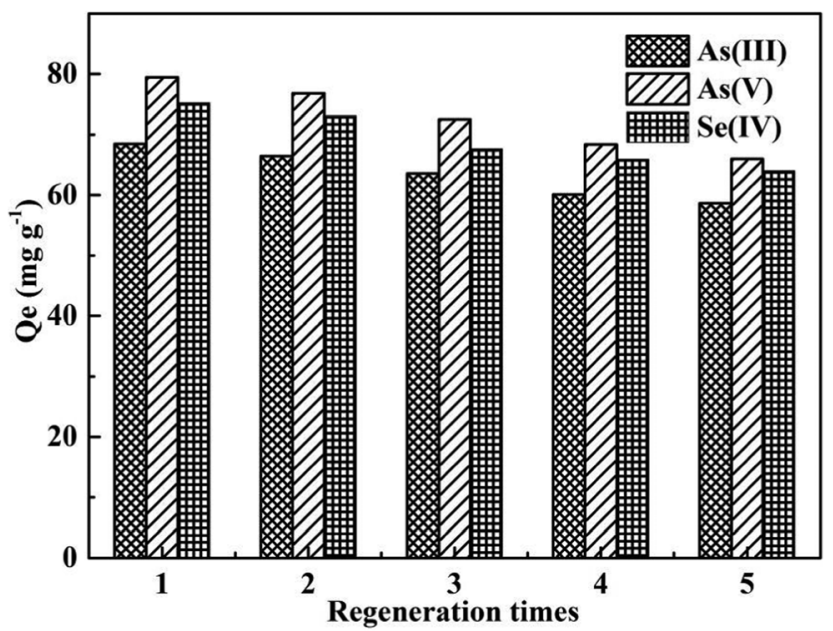

Fig. 5 Adsorption capacities of As(III), As(v) and Se(Iv) on FeOOH microboxes in consecutive adsorption-desorption cycles.

\subsection{Adsorption mechanism}

To clarify the reason for its superior adsorption performance, the electronic configuration and atomic geometrical distribution of the $\mathrm{FeOOH}$ microboxes before and after adsorption of As(III) and As(v) were measured by X-ray absorption fine spectroscopy (XAFS).

In general, heavy metal ions like As and Se are adsorbed on FeOOH nanomaterials through ion exchange, where the surface hydroxyl groups play the main role, being involved in the ion
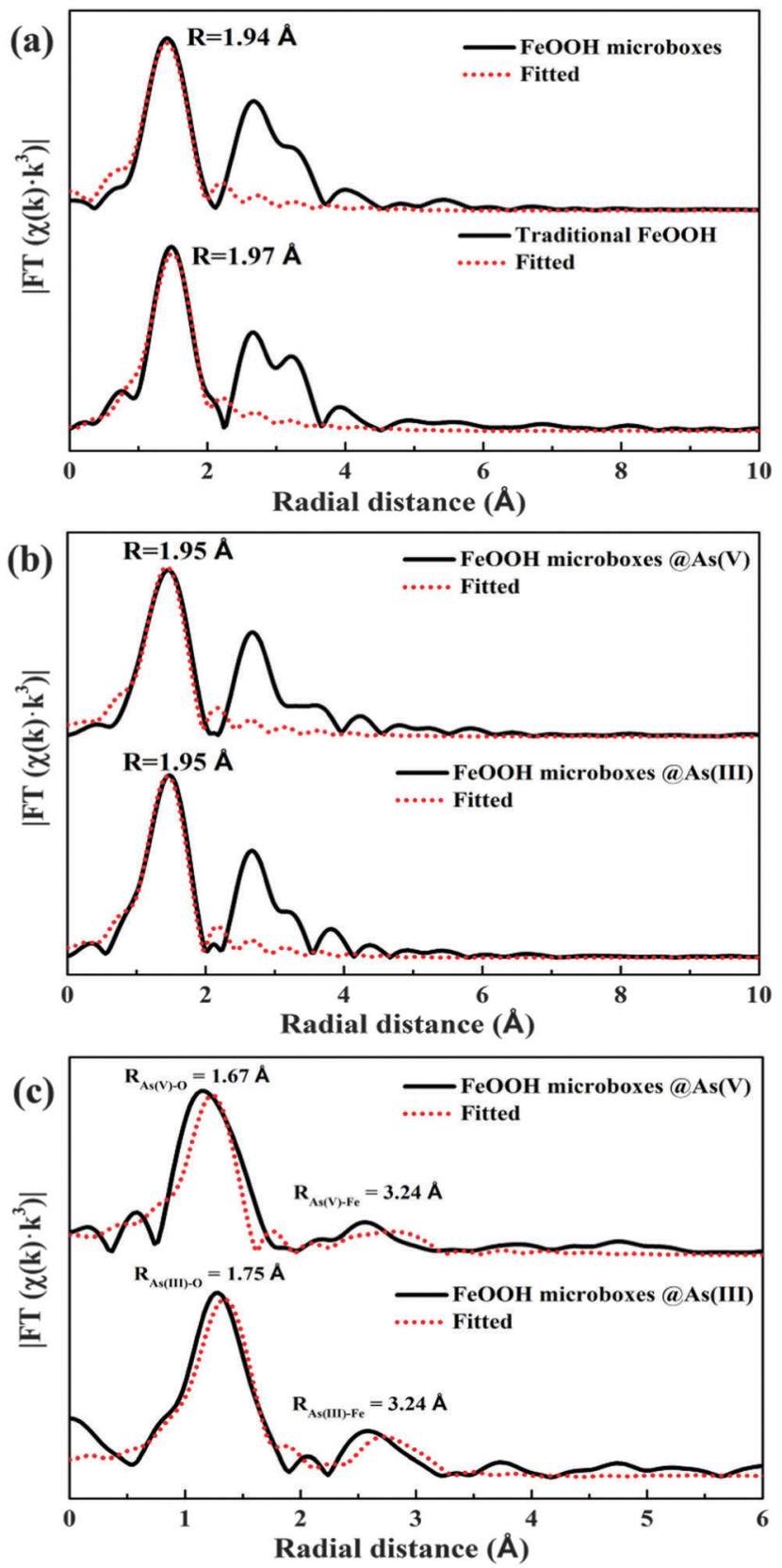

Fig. 6 EXAFS spectra of Fourier transforms of $k^{3} \chi(k)$ into $R$ space, where the red dotted lines correspond to the curve-fitting results: (a) Fe K edge in Fe-containing samples, (b) Fe $\mathrm{K}$ edge in Fe-containing samples after adsorbed As(III) and As(V), and (c) As K edge in As-adsorbed samples. 
exchange process during anion adsorption. The reaction equations are listed below (eqn (5) to (10)): ${ }^{8,12,41}$

$$
\begin{array}{r}
\equiv \mathrm{FeOH}+\mathrm{AsO}_{4}{ }^{3-}+\mathrm{H}^{+}=\equiv \mathrm{FeOAsO}_{3}{ }^{2-}+\mathrm{H}_{2} \mathrm{O} \\
\equiv(\mathrm{FeOH})_{2}+\mathrm{AsO}_{4}{ }^{3-}+2 \mathrm{H}^{+}=\equiv(\mathrm{FeO})_{2} \mathrm{AsO}_{2}{ }^{-}+2 \mathrm{H}_{2} \mathrm{O} \\
\equiv \mathrm{FeOH}+\mathrm{AsO}_{3}{ }^{3-}+\mathrm{H}^{+}=\equiv \mathrm{FeOAsO}_{2}{ }^{2-}+\mathrm{H}_{2} \mathrm{O} \\
\equiv(\mathrm{FeOH})_{2}+\mathrm{AsO}_{3}{ }^{3-}+2 \mathrm{H}^{+}=\equiv(\mathrm{FeO})_{2} \mathrm{AsO}^{-}+2 \mathrm{H}_{2} \mathrm{O} \\
\equiv \mathrm{FeOH}+\mathrm{SeO}_{3}{ }^{2-}+\mathrm{H}^{+}=\mathrm{FeOSeO}^{-}+\mathrm{H}_{2} \mathrm{O} \\
\equiv(\mathrm{FeOH})_{2}+\mathrm{SeO}_{3}{ }^{2-}+2 \mathrm{H}^{+}=\equiv(\mathrm{FeO})_{2} \mathrm{SeO}+2 \mathrm{H}_{2} \mathrm{O}
\end{array}
$$

The results of the Fourier-transformed (FT) $k^{3}$-weighted EXFAS oscillations into $R$ space of $\mathrm{Fe}$ or As edge in $\mathrm{FeOOH}$ microboxes before and after adsorption were shown in Fig. 6 . The bond distance of $\mathrm{Fe}-\mathrm{O}$ in $\mathrm{FeOOH}$ hollow microboxes before adsorption was $1.94 \AA$, which was maintained after adsorption (1.95 ̊). Similar to the changes of $\mathrm{Fe}-\mathrm{O}$ bond distance, the As-O bond distance also exhibited hardly any difference, changing from $1.69 \AA$ A before adsorption (Fig. S6, ESI $\dagger$ ) to $1.67 \AA$ after adsorption. These data demonstrated that there was no oxidation reaction during the $\mathrm{As}(\mathrm{v})$ adsorption processes by the as-synthesized $\mathrm{FeOOH}$ microboxes. This conclusion could also be verified by the X-ray adsorption near edge structure (XANES) results of the As-adsorbed samples shown in Fig. S7 (ESI $\dagger$ ). After being adsorbed by the $\mathrm{FeOOH}$ microboxes, the bond energy of As(v) was $11873.3 \mathrm{eV}$ and As(III) was $11869.5 \mathrm{eV}$, which was the same as the reference samples of $\mathrm{As}(\mathrm{v})(11873.3 \mathrm{eV})$ and As(III) (11869.5 eV) before adsorption.

However, the As-Fe distance was found to be $3.24 \AA$ in both As(III) and As(v) adsorbed samples, corresponding to bidentate binuclear corner-sharing $\left({ }^{2} \mathrm{C}\right)$ complexes, ${ }^{42}$ which demonstrated that the adsorption reaction took place between the surface hydroxyl groups and the heavy metal contaminants. That is, the favorable adsorption performance of $\mathrm{FeOOH}$ microboxes was related with its ample surface active sites.

Thus, XAFS was utilized to confirm the ample surface active sites of the as-synthesized FeOOH microboxes. Meanwhile, the irregular structured traditional FeOOH (Fig. S8, ESI $\dagger$ ), which exhibited interior adsorption capacities, was applied as the reference (Table 2). First, the XANES was determined and is shown in Fig. 7. Both the pre-edge peaks (the fingerprint XANES peaks below the adsorption edges) and the post-edge regions (the XANES patterns above the absorption edges) of Fe K XANES in $\mathrm{FeOOH}$ microboxes were similar to those in the standard $\mathrm{Fe}_{2} \mathrm{O}_{3}$. The absorption edge energy of first-order derivatives in the Fe species in the $\mathrm{FeOOH}$ microboxes samples was $7127.7 \mathrm{eV}$, higher than that of traditional $\mathrm{FeOOH}$ at $7123.4 \mathrm{eV}$, corresponding to the higher valence of the $\mathrm{Fe}(\mathrm{III})$ in the microboxes. This high valence state of Fe endowed the $\mathrm{FeOOH}$ hollow structure with more unoccupied orbitals for linking with hydroxyl groups. ${ }^{43}$ Furthermore, according to the results of the Boehm titration (Fig. S9, ESI $\dagger$ ), a larger amount of protons were needed to change the $\mathrm{pH}$ value in case of the FeOOH microboxes, which clearly confirmed that a high content of hydroxyl groups was present on the surface of the hollow structures. Furthermore, from the results of EXFAS (Fig. 6a), the Fe-O bond distance of $\mathrm{FeOOH}$ microboxes was $1.94 \AA$, which was shorter than that of traditional FeOOH (1.97 $)$ ). The decrease of metal-ligand bond length in the $\mathrm{FeOOH}$ microboxes might be derived from the electron cloud migration, resulting in a stronger covalent effect. ${ }^{44,45}$ Additionally, the corresponding $\mathrm{H}-\mathrm{O}$ bond tended to be more ionic and less stable, ${ }^{45}$ thereby the $\mathrm{H}-\mathrm{O}$ bond of the $\mathrm{FeOOH}$ microboxes was more reactive. ${ }^{41}$ In combination with the ample surface active sites, the favorable adsorption performance of $\mathrm{FeOOH}$ microboxes on heavy metal ion purification can be well explained in terms of adsorption reactions.
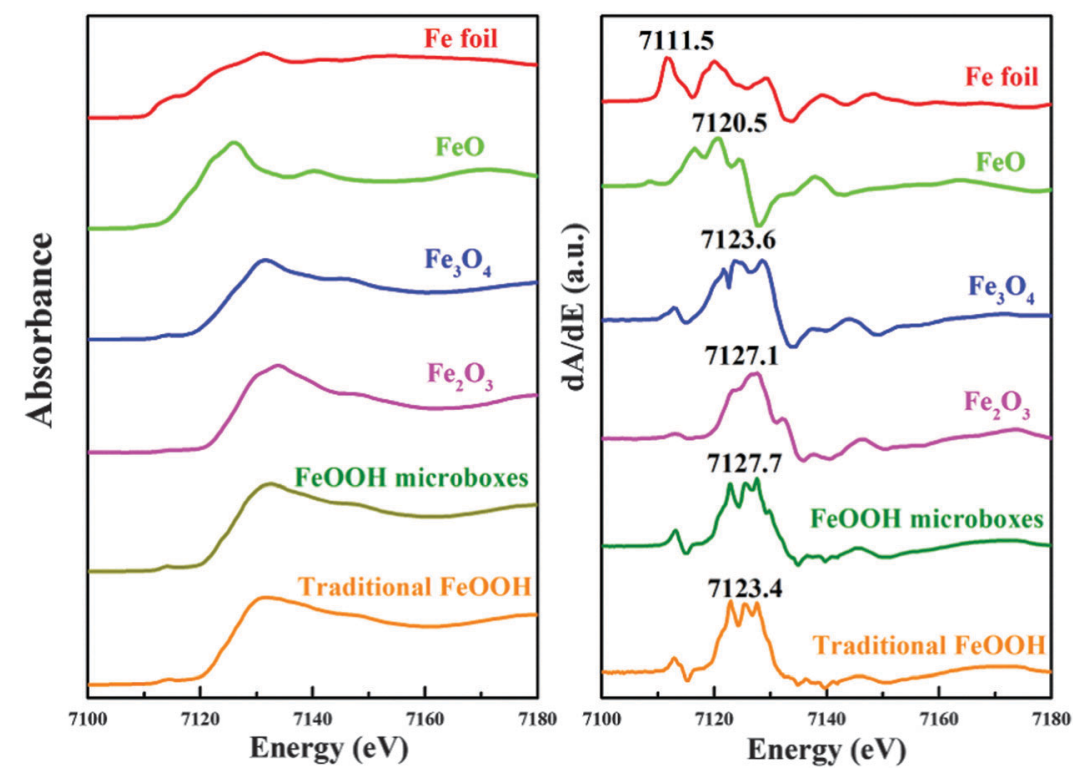

Fig. 7 Normalized XANES and first-order derivates of XANES of Fe $\mathrm{K}$ edge in Fe-containing and reference samples. 
Another dominant difference between the $\mathrm{FeOOH}$ microboxes and conventional $\mathrm{FeOOH}$ was the microstructure. The as-synthesized $\mathrm{FeOOH}$ microboxes were assembled from numerous 2D nanosheets generated from interfacial reactions, followed by the formation of crosslinks in the same chemical environment. This special structure provided channels that facilitated the transport and migration of contaminants into the interior. Besides, it also guaranteed the existence of a homogeneous valence state of $\mathrm{Fe}(\mathrm{III})$ for the entire material, which signified ample hydroxyl sites with high reactivity in both the exterior and interior of the assynthesized FeOOH microboxes.

\section{Conclusions}

In summary, microboxes constructed from numerous $\mathrm{FeOOH}$ nanosheets were successfully prepared through a templateengaged reaction, which exhibited superior adsorption performance toward aqueous As(III), As(v) and Se(Iv), with the maximum adsorption capacities of $192.19 \mathrm{mg} \mathrm{g}^{-1}, 250.01 \mathrm{mg} \mathrm{g}^{-1}$ and $169.88 \mathrm{mg} \mathrm{g}^{-1}$, respectively. The results of XAFS indicated that Fe with high valence and short $\mathrm{Fe}-\mathrm{O}$ bond distance was present on the structure during the formation process, ensuring the presence of ample hydroxyl sites and stronger bonding capacity for the adsorption of heavy metals, which was unambiguously confirmed by the Boehm titration. According to the superior adsorption performance induced by the abundant surface hydroxyl groups, it is reasonable to speculate that the $\mathrm{FeOOH}$ hollow structures could be used as an ideal adsorbent in the removal of aqueous heavy metals. Furthermore, we also anticipate that the hollow microboxes derived from Prussian blue would be promising materials in environmental remediation.

\section{Acknowledgements}

Financial supported by the National Science Fund for Distinguished Young Scholars of China (Grant No. 51225805) and the Funds for Creative Research Groups of China (No. 51221892).

\section{References}

1 J. Giménez, J. Pablo, M. Martínez, M. Rovira and C. Valderrama, J. Colloid Interface Sci., 2010, 348, 293-297.

2 Q. L. Zhang, T. C. Lin, X. Chen and N. Y. Gao, J. Hazard. Mater., 2007, 148, 671-678.

3 C. Han, H. Li, H. Pu, H. Yu, L. Deng, S. Huang and Y. Luo, Chem. Eng. J., 2013, 217, 1-9.

4 A. Anjum, P. Lokeswari, M. Kaur and M. Datta, J. Anal. Sci., Methods Instrum., 2011, 1, 25-30.

5 H. Liu, K. C. Zuo and C. D. Cecitis, Environ. Sci. Technol., 2014, 48, 13871-13879.

6 E. A. Deliyanni, D. N. Bakoyannakis, A. I. Zouboulis and K. A. Matis, Chemosphere, 2003, 50, 155-163.

7 R. Watkins, D. Weiss, W. Dubbin, K. Peel, B. Coles and T. Arnold, J. Colloid Interface Sci., 2006, 303, 639-646.
8 S. Kongsri, K. Janpradit, K. Buapa, S. Techawongstien and S. Chanthai, Chem. Eng. J., 2013, 215-216, 522-532.

9 X. Sun, C. Hu, X. Hu, J. Qu and M. Yang, J. Chem. Technol. Biotechnol., 2013, 88, 629-635.

10 M. C. S. Faria, R. S. Rosemberg and C. A. Bomfeti, Chem. Eng. J., 2014, 237, 47-54.

11 S. Hasan, A. Ghosh, K. Race, R. Schreiber and M. Prelas, Sep. Sci. Technol., 2014, 49, 2863-2877.

12 M. Martínez, J. Giménez, J. de Pablo, M. Rovira and L. Duro, Appl. Surf. Sci., 2006, 252, 3767-3773.

13 Y. Fu, J. Y. Wang, Q. X. Liu and H. B. Zeng, Carbon, 2014, 77, 710-721.

14 M. Chhowalla, H. S. Shin, G. Eda, L.-J. Li, K. P. Loh and H. Zhang, Nat. Chem., 2013, 5, 263-275.

15 C. Ataca, H. Şahin and S. Ciraci, J. Phys. Chem. C, 2012, 116, 8983-8999.

16 X. Y. Yu, T. Luo and Y. Jia, et al., J. Phys. Chem. C, 2011, 115, 22242-22250.

17 X. B. Wang, W. P. Cai and G. Z. Wang, et al., CrystEngComm, 2013, 15, 2956-2965.

18 H. Hwang, H. Kim and J. Cho, Nano Lett., 2011, 11, 4826-4830.

19 Y. Yan, X. Ge, Z. Liu, J. Y. Wang, J. M. Lee and X. Wang, Nanoscale, 2013, 5, 7768-7771.

20 S. Ding, J. S. Chen and X. W. Lou, Chemistry, 2011, 17, 13142-13145.

21 Y. Shi, T. Wang, J. I. Wong, Y. A. Tan, L. C. Hsu, L. J. Li, Y. C. Lu and H. Y. Yang, Sci. Rep., 2013, 3, 2169.

22 Z. Tang, S. Shen, J. Zhuang and X. Wang, Angew.Chem., 2010, 49, 4603-4607.

23 X. Lai, J. Li, B. A. Korgel, Z. Dong, Z. Li, F. Su, J. Du and D. Wang, Angew. Chem., 2011, 50, 2738-2741.

24 Z. Jiang, H. Sun, Z. Qin, X. Jiao and D. Chen, Chem. Commun., 2012, 48, 3620-3622.

25 R. Ameloot, F. Vermoortele, W. Vanhove, M. B. Roeffaers, B. F. Sels and D. E. Vos, Nat. Chem., 2011, 3, 382-387.

$26 \mathrm{M}$. Hu, A. A. Belik, M. Imura and Y. Yamauchi, J. Am. Chem. Soc., 2013, 135, 384-391.

27 R. J. Atkinson, A. M. Posner and J. P. Quirk, J. Inorg. Chem., 1972, 34, 2201-2211.

28 M. Newville, J. Inorg. Chem., 1972, 34, 2201-2211.

29 L. Zhang, H. B. Wu, S. Madhavi, H. H. Hng and X. W. Lou, J. Am. Chem. Soc., 2012, 134, 17388-17391.

30 C.-Y. Cao, W. Guo, Z.-M. Cui, W.-G. Song and W. Cai, J. Mater. Chem., 2011, 21, 3204-3209.

31 N. Yamazoe, Y. Teraoka and T. Seiyama, Chem. Lett., 1981, 1767-1770.

32 L. Zhang, H. B. Wu and X. W. Lou, J. Am. Chem. Soc., 2013, 135, 10664-10672.

33 Y. Sun, X. Hu, W. Luo, H. Xu, C. Hu and Y. Huang, ACS Appl. Mater. Interfaces, 2013, 5, 10145-10150.

34 K. H. Goh and T. T. Lim, Chemosphere, 2004, 55, 849-859.

35 B. A. Manning, S. E. Fendorf and S. Goldberg, Environ. Sci. Technol., 1998, 32, 2383-2388.

36 C.-Y. Cao, W. Guo, Z.-M. Cui, W.-G. Song and W. Cai, J. Mater. Chem., 2011, 21, 3204-3209. 
37 K. Zhang, V. Dwivedi, C. Chi and J. Wu, J. Hazard. Mater., 2010, 182, 162-168.

38 M. Szlachta and N. Chubar, Chem. Eng. J., 2013, 217, 159-168.

39 C.-Y. Cao, Z.-M. Cui, C.-Q. Chen, W.-G. Song and W. Cai, J. Phys. Chem. C, 2010, 114, 9865-9870.

40 G. S. Zhang, F. D. Liu, H. J. Liu, J. H. Qu and R. P. Liu, Environ. Sci. Technol., 2014, 48, 10316-10322.

41 S. J. Grabowski, Tetrahedron, 1998, 54, 10153-10160.
42 G. O. Nguema, G. Morin, F. Juillot, G. Calas and G. E. Brown, Environ. Sci. Technol., 2005, 39, 9147-9155.

43 S. Dulnee and A. C. Scheinost, Environ. Sci. Technol., 2014, 48, 9341-9348.

44 B. C. Melot, D. O. Scanlon, M. Reynaud, G. Rousse, J. N. Chotard and M. Henry, ACS Appl. Mater. Interfaces, 2014, 6, 10832-10839.

45 M. Szlachta and N. Chubar, Chem. Eng. J., 2013, 217, 159-168. 